\title{
The Transformation of the Clinic and the Epidemiology of Diseases: The Times they are a Changing
}

\section{Turabian JL*}

Specialist in Family and Community Medicine, Health Center Santa Maria de Benquerencia, Spain

*Corresponding author: Jose Luis Turabian, Health Center Santa Maria de Benquerencia Toledo, Spain, Email: jturabianf@hotmail.com

\section{Review Article}

Volume 3 Issue 3

Received Date: October 17, 2019

Published Date: November 11, 2019

DOI: $10.23880 /$ eij-16000131

\section{Abstract}

Traditionally, the diagnosis has focused on the symptoms, which must be ordered so that they can be integrated into the intelligible sets of diseases. General medicine and epidemiology, each one for their part, have traditionally tried to identify, catalogue diseases and health problems. But, the diseases are, at each time, different: the gold standards disappear or are attenuated for the diagnosis of many health problems, which brings with it a number of imperfect clinical and research criteria used, with symptoms that overlap and cause biases by misclassification in epidemiological studies. Currently there is a tremendous acceleration in the transformation of disease symptoms, favoured by a series of factors that overlap and feedback: 1) The greater access to medical services and the early treatment of many diseases or symptoms; 2) The health paradox; 3) The evolution of the cultural context; 4) The medicalization of symptoms and risk factors; 5) Overdiagnosis; 6) Overtreatment; 7) The creation of new disea ses; 8) The overuse of prevention; 9) The presence of multimorbidity and polypharmacy; 10) The high frequency of adverse drug reactions and drug-drug interactions; And 11) The epidemiological transitions. Consequently, we must see the new symptoms that make up new pathological entities, as if they were living beings that beat, such as the notes in a musical score or the figures of mysterious constellations. A new way of classifying diseases according to their symptoms is necessary, which may include categories of classification as simple / complicated, transitional, and unordered (chaotic), "warm" or "cold"; problems that "advance" or "recede"; "expanding", or "contracting", that jump from centrality to eccentricity, from bustle to silence, or vice versa.

Keywords: Epidemiology; Community Medicine; General practitioner; Overdiagnosis; Disease; Diagnosis; Definition; Misclassification; Multimorbidity; Polypharmacy; Drug-Related Side Effects; Adverse Reactions

For the times they are a-changing

The slow one now

Will later be fast

As the present now

Will later be past

The order is rapidly fading'
And the first one now

Will later be last

For the times they are a-changing

'Bob Dylan (American singer-songwriter, author, and visual artist). The Times They Are A Changing' 1964 


\section{Introduction}

Traditionally, the diagnosis has focused on the symptom. Disease is a medical entity characterized by specific signs and symptoms. Disease is a condition that causes a certain process and that result in a certain status that alters the ontological state of health of a living being. In this way, the evaluation and management of symptoms is a main task in general medicine. The general practitioner aims to move in the direction of ordering the symptoms and signs, so that he can catalogue the diseases that may appear disorderly, integrating and ordering the symptoms in an intelligible set [1-4]. This task of cataloguing the symptoms to be able to label and classify health problems, has an obvious and transcendental epidemiological implication, since it is the basis of the data on the incidence and prevalence of diseases, the methodology of epidemiological studies and clinical trials, and of mortality, which are all key factors to developing global health strategies [5].

The symptom is an important concept in medicine. However, the omnipresence of the symptom seems not to be reflected in an equally prominent curiosity aimed at investigating this concept as a phenomenon [6]. At least three symptom definitions have been reported:

1. Symptom is a subjective indication of a disease or a change in the condition as perceived by the patient. Many symptoms are accompanied by signs (apparently objective). Some symptoms can be objectively confirmed.

2. Symptom is any subjective evidence of disease. On the contrary, a sign is objective (theoretically). Epistaxis is a signal; it is evident to the patient, the doctor and others. Anxiety, low back pain and fatigue are symptoms; only the patient can perceive them.

3. A symptom is a deviation from normal function or sensation noticed by a patient, which reflects the presence of an unusual state or a disease. A symptom is subjective, observed by the patient, and cannot be measured directly.

Some symptoms often occur at the same time with each other and are known as a syndrome. For example, depression, fatigue and pain accompany most cancers, or symptom clusters in patients with acute coronary syndrome, or symptom clusters in individuals with chronic kidney disease. But, individual symptoms comprising a cluster can vary widely, and different biopsychosocial factors influence its presentation. For example, the symptoms expressed by patients who experience an acute coronary disease, are different in the stages of family life cycle, so it there may be modulated groups of patients showing specific patterns of presentation of symptoms and signs. This knowledge may be useful to physicians for diagnosis, and providing additional information to factors risk [7].

On the other hand, a symptom can be a cause (e.g., Fatigue as a cause of a fall), it can be an effect (e.g., Depression as an effect of the loss of a loved one), it can be both (e.g., depression as an effect of the loss of a loved one and as a cause of suicide), but symptoms usually act as a fact associated with various diseases [8].

Symptoms represent a somatic manifestation of the disease but can also be a consequence of treatment. Symptoms are of vital importance, as they are a signal to a person that there is a threat to health, side effects of treatment or a manifestation of an acute illness or disease progression that requires urgent attention. As people often experience multiple symptoms simultaneously, this increases the burden of the patient's suffering. The groups of symptoms can be defined as two or more symptoms that occur simultaneously and are related (co-morbidity), but multiple symptoms of different health problems not necessarily physiopathologically related (multimorbidity) can also occur. Symptoms represent a somatic manifestation of the disease but can also be a consequence of treatment. Symptoms are of vital importance, as they are a signal to a person that there is a threat to health, side effects of treatment or a manifestation of an acute illness or disease progression that requires urgent attention. As people often experience multiple symptoms simultaneously, this increases the burden of the patient's suffering. The groups of symptoms can be defined as two or more symptoms that occur simultaneously and are related (co-morbidity), but multiple symptoms of different health problems not necessarily physiopathologically related (multimorbidity) can also occur [9].

The interpretation and meaning that the individual attributes to the symptoms or discomforts, are influenced by different variables such as previous personal experiences with the symptom, family experiences or other significant actors, learned models, beliefs and social norms. All these factors not only influence the perception of the individual, but at the same time shape the reaction to the symptoms as a result of their cognitive process. In addition, the reason for consultation expressed by the patient is a "manifest content." The attending physician must transform or complete those ideas that are latent or initially hidden. The latent content of the symptom may be incomprehensible at first; when the patient's initial manifest material is translated by the attending physician, we have a more understandable expression. Patients' messages contain "facts" and "feelings", and 
the manifest symptom that the patient initially expresses is a "symbolic representation" [10].

Getting sick is a social process; It implies a social label and it is this definition of the state of the person that allows him to behave like a sick individual. This label may imply stigma: a social construction that defines people in terms of a distinctive feature or brand, and devalue that person as a consequence. Stigma can have an effect on various aspects of the disease experience, including the search for health care, diagnostic tests and access to treatment and other support services. The symptoms are mediators in the personal evaluation of the disease, and are also influenced by health beliefs (the locus of control), psychological characteristics (anxiety, anger, depression, optimism) and available social support. The symptoms expressed by patients in the general medicine practice may therefore have different meanings: expressions of biochemical alterations, symbolic expressions, expressions of the group context, expressions of family stress when going through developmental transactions, expressions of coping with a situation or event, expressions of the symptoms of "family character or style" (similar in the family), somatic expressions associated with mental problems and functional or psychosocial expressions associated with organic problems, or social and historical expressions [11].

When the description of the diseases in the oldest books is read, for example in the Hippocratic ones or, many centuries later, in those of the doctors of the beginning of the Modern Age, or, almost in our times, in the 19th century, It is difficult for us, on many occasions, to identify these diseases in relation to those we know today. We usually blame it on the imperfect observation of the old masters and their deformation by theories and systems. But, in reality, it is something else: diseases are, at each time, different; they evolve over time. Thus the same disease changes over the course of generations and, sometimes, within the scope of a single generation [12]. Diseases, in addition to changing over time, change with economic development, culture, environmental changes, and other factors. Thus, in the last 20 years there have been important changes in infectious diseases, new diseases have appeared, others have disappeared, etc. During the professional life of a doctor many diseases will change and new forms of treatments make serious diseases controllable or preventable, and others will emerge that will occupy the holes created. In addition, the division between sick and healthy is not discontinuous or dichotomous, but constitutes a continuum, and in this way the accepted diagnostic categories may vary throughout history [13].

This transformation, which is in slow and gradual in some times, occurs at other times in history with singular rapidity; and maybe never like now; surely because of the resounding change due to active medications and the progress of hygiene and dietetics, and social changes. In this way, the symptomatology of many diseases has been altered or transformed by the advances of the therapy (cure - as in infections, attenuation of symptoms and syndromes, complications from the use of drugs, new symptoms, etc.) [12].

Thus, for example, it has been reported that among adults aged 35-70 years, cardiovascular disease is the major cause of mortality globally. However, in high income countries and some upper-middle income countries, deaths from cancer are now more common than those from cardiovascular disease, indicating a transition in the predominant causes of deaths in middle-age. As cardiovascular disease decreases in many countries, mortality from cancer will probably become the leading cause of death. On the other hand, the high mortality in poorer countries is not related to risk factors, but it might be related to poorer access to health care [5].

In this scenario, the objective of this article, based on the narrative review of selected articles and the personal experience of the author, is to reflect, conceptualize, synthesize and discuss the possible implications, which for the understanding of the clinical physician and for the epidemiological research, It has the transformation of clinical symptoms, in relation to changes in prevalence and diagnosis in the general population.

\section{Discussion}

\section{Symptom is an Epiphenomenon}

Symptom can be considered only a signal, or an epiphenomenon, a secondary phenomenon that accompanies or follows a primary phenomenon without constituting an essential part of it and without seemingly exerting influence; The somatic origin of the symptoms (for example, emotion or pain), is the effect of a physiological change that shows it. In medicine, this relationship with the primary phenomenon is generally not implied, and only correlation, not causation, is known or suspected. In this sense, to say that " $\mathrm{X}$ " is associated with "Y" as epiphenomenon is to recognize that the correlation does not imply causation. Clinical signs, symptoms, syndromes and risk factors may be epiphenomena in this regard [14].

\section{Symptoms are the Result of an Interpretation Process}

Symptoms do not appear as such; the symptoms are rather the result of an interpretation process [4]. It is admitted that there are gaps in the knowledge of the 
mechanisms of expression of symptoms, such as for example regarding the symptoms of inflammation or immune function, and whether or not the symptoms are mechanically related. There have also been limitations for prior investigation of symptom groups, including the lack of standard measures of symptoms. On the other hand, it is a fact that patients frequently experience multiple symptoms simultaneously [9].

In addition, symptoms involve psychosocial factors in patients. For example, in mental health disorders, in which phenomenon of stigma still exists. Consequently, symptoms can be misdiagnosed and sometimes treated improperly, because doctors rely exclusively on a verbal interview with patients for diagnosis. Since this diagnostic method is likely to be determined by the way in which patients present their symptoms, it is essential to take into account how patient communication practices determine diagnosis. In this regard, it has been reported that when patients present with mental health symptoms simply by describing the symptoms, primary care physicians show a preference for providing a physical health diagnosis; On the contrary, when patients provide a concrete link between their symptoms and the way in which the symptoms are altering their daily lives, primary care physicians usually provide a mental health diagnosis [15].

It should be borne in mind that the experiences of symptoms are embedded in a complex interaction between biological, psychological and cultural factors $[4,6,11,16]$.

From a biomedical perspective, symptoms are considered possible indicators of disease and are characterized by parameters related to severity (for example, appearance, severity, impact and temporal aspects). However, such characteristics of the symptoms are rarely unambiguous, but simply indicate the probability of disease. In addition, the doctor's interpretation of the presenting symptoms will also be influenced by other factors. From a psychological perspective, the factors that affect interpretation depend on the focus frame (for example, the internal frame of reference, attention to sensations, perception of the disease and susceptibility to suggestion). These individual factors cannot be alone either, but are influenced by the environment. Anthropological research suggests that personal experiences and culture form a relationship of continuous feedback that influences when and how feelings are understood as disease symptoms and acts on them [4].

\section{Different Approaches to the Interpretation of Symptoms Imply that we must be Cautious when Interpreting the Results of Symptom Prevalence}

Different approaches to the interpretation of symptoms implies that we must be cautious and aware when interpreting the results of the surveys on which are based prevalence of symptoms in the general population or in primary care. These findings will reflect a variety of interpretations of sensations, which are not equivalent to the expressions of the underlying disease. In addition, if the diagnosis of the disease is based exclusively on the presence of specific characteristics of the symptoms, we can risk reinforcing a dualistic approach, including the medicalization of normal phenomena and the devaluation of medically unexplained symptoms. Future research in primary care could benefit from exploring symptoms as a generic phenomenon and raising awareness of the complexity of symptoms [4].

An example that reminds us of the need to be cautious with the interpretation of symptoms is the presence of "disorganized or medically unexplained symptoms", which represents a major challenge for healthcare systems in industrialized countries. Between $50-70 \%$ of the patients treated present disorganized symptoms or diseases; therefore, account for the majority of patients cared for in family medicine. What are disorganized diseases? They are those symptoms or problems that give the doctor a feeling of insecurity with respect to the traditional diagnostic categories, and at the same time on expectation about its evolution [1719]. In addition, the transformation of the symptoms makes that conclusions of studies epidemiological and clinical trials are difficult to assess, and should remind us of the caution with which they should be taken [20].

General medicine and epidemiology, each one for their part, have traditionally tried to identify, catalog diseases and health problems. However, this traditional and independent approach to both disciplines is becoming inadequate to face a changing disease landscape. The main challenges for human health are chronic non-communicable diseases, often driven by altered immunity and inflammation, and contagious infections of agents harbouring antibiotic resistance. Although the evolution of the clinic and medicine has been pointed out for a long time, we are currently witnessing a tremendous acceleration of such evolution, favoured by the presence of a series of factors that overlap and feedback (Table 1). Therefore, we can now speak of an evolution of the clinical and epidemiology of health problems [21-24]. So, classic description of symptoms of new diseases is less and less useful. At present, the symptoms of many diseases are changing. And this phenomenon is produced by the conjunction of several causes, such as: 


\section{Epidemiology International Journal}

\begin{tabular}{|c|c|}
\hline $\begin{array}{c}\text { Causes of Changes of Symptoms of Many } \\
\text { Diseases }\end{array}$ & Concepts \\
\hline $\begin{array}{l}\text { 1. The greater access to medical services and the } \\
\text { early treatment of many diseases or symptoms }\end{array}$ & $\begin{array}{l}\text { Only the first or lightest symptoms are observed, before } \\
\text { treatment }\end{array}$ \\
\hline 2. The health paradox & $\begin{array}{l}\text { The feeling of being sick is greater the better the objective data, } \\
\text { such as life expectancy }\end{array}$ \\
\hline $\begin{array}{l}\text { 3. The evolution of the cultural context causes all } \\
\text { the phenomena of life to be experienced, } \\
\text { including those of the disease, in an urgent, } \\
\text { demanding, excessive, and exaggerated way }\end{array}$ & $\begin{array}{l}\text { Disease is lived in an urgent, demanding, excessive, and } \\
\text { exaggerated way, both by the patient and by the doctor }\end{array}$ \\
\hline $\begin{array}{l}\text { 4. The medicalization of symptoms and risk } \\
\text { factors }\end{array}$ & $\begin{array}{l}\text { The practical imprecision of the term "risk factors", that is, the } \\
\text { characteristics statistically associated with a disease or injury } \\
\text { (not a cause, but a simple statistical association), has made any } \\
\text { variable that can predict the value of the disease be called "risk } \\
\text { factor", and then assigned the same meaning as causal factor }\end{array}$ \\
\hline 5. Overdiagnosis & $\begin{array}{l}\text { Overdiagnosis occurs when a diagnosis is "correct" in } \\
\text { accordance with current professional standards, but the } \\
\text { diagnosis or associated treatment has a low probability of } \\
\text { benefiting the diagnosed person. }\end{array}$ \\
\hline 6. Overtreatment & $\begin{array}{l}\text { Over-treatment refers to the unnecessary treatment of a } \\
\text { condition }\end{array}$ \\
\hline 7. Creation of new diseases & $\begin{array}{l}\text { Many processes that were previously foreign to medicine have } \\
\text { been explained and treated by doctors }\end{array}$ \\
\hline 8. Overuse of prevention & $\begin{array}{l}\text { The Implementation of the guidelines on prevention of diseases } \\
\text { in clinical practice would classify most adult at high risk }\end{array}$ \\
\hline 9. Presence of multimorbidity and polypharmacy & $\begin{array}{l}\text { Multimorbidity is common at all ages and cannot be understood } \\
\text { based on common disease combinations. }\end{array}$ \\
\hline $\begin{array}{l}\text { 10. The high frequency of adverse drug reactions } \\
\text { and drug-drug interactions }\end{array}$ & $\begin{array}{l}\text { The increase in multimorbidity and polypharmacy brings with } \\
\text { it a dramatic increase in adverse drug reactions and drug-drug } \\
\text { interactions }\end{array}$ \\
\hline 11. Epidemiological transitions & $\begin{array}{l}\text { As socioeconomic status and access to health care improve, the } \\
\text { disease burden of a population tends to undergo an } \\
\text { epidemiological transition }\end{array}$ \\
\hline
\end{tabular}

Table 1: Causes of Changes of Symptoms of Many Diseases.

The Greater Access to Medical Services: Diseases have their distinctive patterns of their natural history: age of onset, course and outcomes. The greater access to medical services and the early treatment of many diseases or symptoms causes only early or lighter symptoms to be observed, the florid observation of a clinical picture being rare; even some tend to disappear (rheumatic fever, tofaceous gout, etc.) $[25,26]$.

The Health Paradox: The feeling of being sick grows while global health improves dramatically. The feeling of being sick is greater the better the objective data, such as life expectancy. It is the frustrating search for "perfect health." In developed countries, the obsession with perfect health has become a predominant pathogen. The medical system, in a world impregnated with the instrumental ideal of science, constantly creates new needs for medical care. But the greater the supply of health, the more people has problems, needs and diseases. Everyone demands that progress put an end to the suffering of bodies, that they maintain the freshness of youth as long as possible and prolong life to infinity $[27,28]$.

The Evolution of the Cultural Context: The evolution of the cultural context causes all the phenomena of life to be experienced, including those of the disease, in an urgent, demanding, excessive, and exaggerated way, 
both by the patient and by the doctor, changing the symptoms experienced (the odynophagia "of a few minutes", or the symptoms of gastroenteritis, or the bite of an insect, are lived as serious situations, motivate to going the emergency room, and the patient usually requests to be treated pharmacologically, even by parenteral route, thinking that the effect will be faster) $[29,30]$.

The Medicalization of Symptoms and Risk Factors: As for example in the pre-diabetes, where a war against "prediabetes" has created millions of new patients and a tempting opportunity for the pharmaceutical industry. But how real is the condition? Expert groups, in a relatively short period of time, eliminated "fasting impaired glucose" and "impaired glucose tolerance" and replaced it with "prediabetes." But, medical and epidemiological data provide weak support for this term; however, it does mean "alarmism." In fact, the data show a progression of prediabetes to diabetes in less than $2 \%$ per year, or less than $10 \%$ in 5 years. (Other studies show even slower rates.) The impulse to diagnose and treat prediabetes has a cost; when they are told they have the condition, many people face psychological and financial burdens when trying to address it. To reduce blood sugar, he has increasingly advocated more aggressive measures, such as medications. This fact has ethical implications: it has been reported that groups of experts that promote aggressive treatment of prediabetes accept large amounts of funds from the manufacturers of diabetes medications.

The new haemoglobin A1c standard of these expert groups, combined with their adoption of an equally broad standard in a different blood sugar test a few years earlier, created approximately 72 million new potential patients with prediabetes in the United States alone, and could create hundreds of millions more if it were adopted worldwide. Many people diagnosed with prediabetes visit doctors more frequently for blood sugar tests and advice on diet and exercise. And so, a great marketing opportunity has opened. Companies have pressured the Food and Drug Administration (FDA) to obtain a stamp of approval on food or supplements, such as coffee, dairy products and sugar substitutes, which they say can help prevent diabetes. So, also, an artisanal industry of specialized fitness trainers emerged to serve a multitude of pre-diabetes patients concerned [31].

Another important example is the increasingly broad criteria of primary prevention treatments for cardiovascular diseases with statins, according to which the number of adults ages 60 to 75 without cardiovascular disease who now are qualify for statin therapy, is significantly increased (from $30 \%$ to $90 \%$ in men and from $20 \%$ to $55 \%$ among women) [32].

In the same line is the example of the criteria of treatment of arterial hypertension (and that motivate criticism by important journals when this rhythm of relaxing inclusion criteria is not accepted immediately) [33].

And so, countless examples in daily practice, such as when a mild ankle sprain requires low molecular weight heparin for three weeks, a headache without risk signs precise an urgent brain MRI, etc.

The practical imprecision of the term "risk factors", that is, the characteristics statistically associated with a disease or injury (not a cause, but a simple statistical association), has made any variable that can predict the value of the disease be called "risk factor", and then assigned the same meaning as "causal factor". Consequently, this medicalist transformation entails the logic of the intervention on the risk factor, which ends up becoming a disease. But in reality is not a disease (for example, hypertension is not a disease, osteoporosis is not a disease, hypercholesterolemia, etc.). However, the medicalist force makes impossible to reverse this trend. In addition, the prevalence of prevention based on risk factors destroys many of the possibilities of clinical and social prevention. It also medicalizes the response to many diseases and health problems that have their best response outside the system since they are related to the "conditions" of life or social determinants [34].

The matching action of risk factors with disease and early treatment has changed the clinic. A little appreciated consequence of modern clinical and public health practices is that the experience of being at risk for disease has converged with the experience of the disease itself. This is especially true for certain chronic diseases, in which early diagnosis and aggressive treatment have resulted in a disease without symptoms and without signs and in which treatments have mainly been directed at altering the future course of the disease. Thus, the following phenomena can be described [35]:

1. New clinical interventions that have directly changed the natural history of the disease

2. The greater biological, clinical and epidemiological knowledge about the risk of chronic disease has given rise to early treatments that change the natural history of the disease

3 . The recruitment of a greater number in diagnoses of chronic diseases through new detection and diagnosis technologies and disease definitions, change the disease clinic

4. New ways of conceptualizing efficacy are changing the clinic in medicine 
5. Diagnostic tests and intensive medical interventions change the symptoms of the disease

Overdiagnosis: Overdiagnosis is defined as the diagnosis of a condition that, if not recognized, would not cause symptoms or harm the patient during his life, and occurs more and more frequently as a result of the detection of cancer and other conditions.

Overdiagnosis occurs when a diagnosis is "correct" in accordance with current professional standards, but the diagnosis or associated treatment has a low probability of benefiting the diagnosed person. It is caused by a variety of factors such as the use of increasingly sensitive tests that identify abnormalities that are indolent, non-progressive or regressive (overdetection), extended definitions of disease, for example, the attention deficit / hyperactivity disorder, etc [36].

Since preventive care is a crucial component of general medicine, overdiagnosis in primary care is an important problem from a public health and epidemiologic perspectives and has far-reaching implications. Overdiagnosis is a known consequence of all screening tests and can be assumed to occur in many more clinical contexts. Overdiagnosis can harm patients by causing over-treatment (with possible associated toxicities), anxiety or depression related to diagnosis, and labelling, or through a financial burden. Many entrenched factors facilitate overdiagnosis, including the increasing use of advanced diagnostic technology, financial incentives, a medical culture that encourages greater use of tests and treatments, limitations in evidence that obscure the understanding of the usefulness of diagnosis, use of non-beneficial screening tests, as well as the extension of disease definitions.

The increasing availability and use of advanced technology also contributes to overdiagnosis. Incidentalomas provide an example of the impact of widespread use of advanced images. About $5-15 \%$ of all abdominal imaging tests performed on asymptomatic people contain incidental findings. Despite the recognition that most of these findings are of little clinical importance, their presence often triggers a cascade of unnecessary sequential diagnostic tests. Other examples are that it is estimated that almost half of thyroid cancers in men and more than $80 \%$ in women in high-resource settings represent an excessive diagnosis, representing more than 500,000 cases; and it is estimated that between $3 \%$ and $90 \%$ of prostate cancers represent an excessive diagnosis. Another example is regarding population screening programs. So, the estimated rates of overdiagnosis of breast cancer range between $1 \%$ and $10 \%$.
On the other hand, there is an uninformed enthusiasm on the part of the population towards screenings, and doctors have little understanding of quantitative information and the performance of tests and treatment, which probably contributes to unnecessary tests and overdiagnosis [37]. That is, overdiagnosis is a side effect of a biomedical approach that can co-found on clinical diagnoses and their epidemiology. Although to a much lesser extent, the psychosocial approach would lead to an invessa situation. Biomedical and biopsychosocial health professionals necessarily differ in the position from which they look at the clinical events and the logic they use to interpret them [1].

Overtreatment: Over-treatment refers to the unnecessary treatment of a condition. It occurs every time the overdiagnosed disease is treated and can affect the individual patient and the wider health system. Overdiagnosed disease does not provide an opportunity to benefit from treatment, so the individual only incurs damages. These potential damages include direct negative consequences of unnecessary treatment itself (such as a wound infection after thyroidectomy to treat an overdiagnosed thyroid cancer) and indirect damage related to the consequences of the resulting subsequent services (such as palpitations resulting from a dose incorrect replacement levothyroxine after thyroidectomy.

Overdiagnosis and over-treatment also produce psychological damage due to the disease that is difficult to estimate, but which can also generate symptoms and diagnostics of new diseases (depression, anxiety) and their corresponding pharmacological treatments [37].

The Creation of New Diseases: Many processes that were previously foreign to medicine have been explained and treated by doctors. Five known strategies of invention of diseases and patients have been described [38-41]:

1. Redefine and increase the prevalence of diseases. Example: affirm that the prevalence of female sexual dysfunction is $43 \%$

2. Promote the treatment of mild or medium severity problems as indications of more serious diseases. Example: irritable bowel syndrome or anxiety

3. Transform the risks into diseases. Example: osteoporosis, or testosterone deficiency syndrome

4. Increase concern about future diseases in healthy populations. Example: osteopenia

5. Convert personal and social problems into diagnosable and in need of treatment health disorders. Example: turn shyness into social phobia

Overuse of Prevention: Tertiary prevention is carried out when the disease has already been established, and 
attempts are made to prevent it from getting worse and complications. The intervention takes place in full illness, its main objective being to eliminate or reduce the consequences of its development. However, there is evidence that certain interventions at this level can lead to more and different symptoms. For example, in tertiary prevention of kidney disease in type 2 diabetic hypertensive patients, where treatment with ARAII can lead to worse renal outcomes, such as an increase in the incidence of microalbuminuria, renal insufficiency and a decrease in the glomerular filtration rate $[42,43]$. Another example would be the Implementation of the 2003 European guidelines on prevention of cardiovascular disease in clinical practice that would classify most adult at high risk for fatal cardiovascular disease [44].

High risk prevention strategies have the disadvantage of their inability to prevent diseases in a large part of the population with a relatively small average risk and where most of the disease cases originate. Expanding criteria that justify individual preventive interventions lead to the treatment of larger and healthier strata of the population $[45,46]$.

Presence of Multimorbidity and Polypharmacy, Which Gives Rise to Different Clinical and Epidemiological Expressions of Diseases: It has been noted that most disease pairs occur more frequently than would be expected if the diseases had been independent, and that multimorbidity is not limited to specific related or more frequent combinations; about $70 \%$ of people with a disease have one or more additional chronic diseases that are not among the most common diseases; that is, multimorbidity is common in all ages and cannot be understood according to the common combinations of diseases [47].

In many cases, care is carried out entirely in somatic terms or using biological protocols, which if applied to each of the patient's problems, contradictions occur and cause new and serious problems such as polymedication, whose prevalence in patients over 65 years reaches $50 \%$, with an average of 9 medications per patient, and can reach $80 \%$ in immobilized elderly patients living in the community $[48,49]$.

\section{The Increase in Adverse Drug Reactions (ADRs) and} Drug-Drug Interactions (DDIs): The increase in multimorbidity and polypharmacy brings with it a dramatic increase in adverse drug reactions and drugdrug interactions, which change disease symptoms [50].

Cascade prescription occurs when a new drug is prescribed to "treat" an adverse reaction caused by another drug, based on the mistaken belief that a new medical condition has developed. Adverse events associated with cascade prescription occur when the second drug increases the severity of the adverse reaction produced by the first drug, or when the second drug exposes the patient to the occurrence of new adverse reactions. The key to preventing the prescription in cascade lies in the prevention and rapid detection of adverse reactions, as well as, having a greater awareness and recognition of the possibility of occurrence of adverse reactions [51].

For example, at the population level, use of propulsives, antipsychotics, and flunarizine have a significant association with the increased risk of Parkinsonism, depending on time and cumulative dose. Drugs associated with Parkinsonism should be used with careful monitoring to prevent drug-induced Parkinsonism [52]. Or, an uncontrolled hypertension is misdiagnosed (or a diagnosis of hypertension is made) when the hypertensive person takes NSAIDs simultaneously to their anti-hypertensive, which interferes with the effect of these drugs and consequently increases the blood pressure figure. This diagnosis based on the false belief that the previous medical condition of hypertension has been out of control, motivates the prescription of new antihypertensive or dose increase (that is, treating the NSAID' ADR as the complication or progression of another disease), originating an unnecessary and dangerous therapeutic cascade.

Of every 100 courses of drug treatment, there are 20 ADRs, between 5 and 25 of clinically observable DDIs and between 15 and 50 potential DDIs, which arrive to 100 in geriatric patients. The current approach to the disease, risk factors and prevention, within the biomedical framework, produces a logarithmic spiral or "the wonderful spiral" or "growth spiral." This spiral follows a geometric progression, not arithmetic: every health problem that health system "cure" leads us, not to another new problem, but to many more. Therefore, we are witnessing a situation of changes in the expression of disease symptoms [53-58].

One study found that the application of individual disease guidelines in a patient with five chronic conditions would result in the prescription of 19 doses of 12 different medications, taken at five time points during the day, and that carries the risk of 10 concomitant interactions or adverse events. Care that is "significantly better" can be significantly worse and a nightmare for the patient [59]. Thus, pharmacological interactions represent a new causal factor of great significance in the transformation of the disease burden, the expression of symptoms, and the modification of the effects of therapeutic interventions, which forces us to rethink work areas set between general medicine and epidemiology. 
Epidemiological Transitions: The main challenges for human health are chronic non-communicable diseases, often driven by altered immunity and inflammation, and contagious infections of agents harbouring antibiotic resistance [23].

As socioeconomic status and access to health care improve, the disease burden of a population tends to undergo an epidemiological transition: populations appear to transition from contracting primarily communicable diseases to developing primarily noncommunicable diseases. Concomitant changes in lifestyle, dietary, and environmental exposures and increased access to health care can similarly shift the distribution of non-communicable diseases, such as increases in lifestyle-related cancers. Identifying and quantifying these shifts in disease burden is crucial to ensure that resource allocation and health-care use are appropriate as local and global demographics change [60].

\section{Conclusion}

An accelerated transformation of the symptoms that were previously considered as indicators of certain diseases is taking place. This change in symptoms brings with it clinical and epidemiological consequences: gold standards disappear or are attenuated for the diagnosis of many health problems, which brings with it a number of imperfect clinical and research criteria used, with symptoms that overlap and originate biases in epidemiological studies. These is caused by diagnostic misclassification, which results in 'false positives' (or 'spurious' cases) and false negatives, and consequently alter prevalence and incidence data, even assuming differences in methodology and geographic variations.

Another danger of the misclassification of the diagnosis, due to the transformation of the symptoms that identify diseases, can be illustrated with the hypothetical example of a disease that presents two subtypes of presentation, and that both share a common factor that defines the diagnosis. Classification of each subtype is essential for treatment and prognosis, they already have a different pathophysiology. The study of a treatment for this disease, if it is done based on a population sample, in the case of a subtype being more frequent than the other, it could be concluded that the treatment is effective for cases of the disease, when it is only for the most frequent subtype, masking its ineffectiveness for the most infrequent subtype, for which treatment could be dangerous.

Similar problems may be occurring in the investigation of other diseases where the danger lies in generalizing the results of studies that use patients with symptoms that are transforming, and that could include people with a variety of diagnoses.

It is proposed to seeing the new symptoms of the new pathological entities, as if they were living beings that beat, in which you can feel their permanent systole, such as the notes in a musical score or the figures of mysterious constellations. A new way of classifying diseases according to their symptoms is necessary to replace the compendium of symptoms or the classifications of the various manifestations of the disease in the different stages of their natural history, which may include new classification categories as simple / complicated, transitional, and unordered (chaotic), "warm" or "cold"; problems that "advance" or "recede"; that "expand", or "contract", that jump from centrality to eccentricity, from bustle to silence.

\section{References}

1. Turabian JL, Perez Franco B (2012) Critically examining the symptoms and diagnoses that are taken for granted in family medicine. Creating an own school. Semergen 38(2): 67-71.

2. Turabian JL, Samarin-Ocampos E, Minier L, PerezFranco B (2015) Learning concepts of diagnosis in family medicine: the "mark robinson sign" - the traces that should not be there. Aten Primaria 47(9): 596-602.

3. Turabian JL, Perez Franco B (2010) The diagnostic concept in family medicine: A view of the landscape. The diagnosis in family medicine. Aten Primaria 42(2): 66-69.

4. Rosendal M, Jarbol DE, Pedersen AF, Andersen RS (2013) Multiple perspectives on symptom interpretation in primary care research. BMC Family Practice 14: 167.

5. Dagenais GR, Leong DP, Rangarajan S, Lanas F, Lopez-Jaramillo P, et al. (2019) Variations in common diseases, hospital admissions, and deaths in middle-aged adults in 21 countries from five continents (PURE): a prospective cohort study. Lancet.

6. Eriksen TE, Risor MB (2014) What is called symptom? Med Health Care Philos 17(1): 89-102.

7. Turabian JL, Baez-Montiel B, Gutierrez-Islas E (2016) Type of Presentation of Coronary Artery Disease According the Family Life Cycle. SM J Community Med 2(2): 1019. 
8. Knapp TR (2018) Symptom: Cause, Effect, Both, or Neither? Clin Nurs Res 27(4): 391-394.

9. DeVon HA, Vuckovic KM (2019) Symptom Clusters: Is the Sum Greater Than the Parts? West J Nurs Res 41(7): 951-953.

10. Turabian JL (2019) Interpretation of the Reasons for Consultation: Manifest and Latent Content. The Initiation of the Diagnostic Process in General Medicine. Archives of Community and Family Medicine 2(1): 1-8.

11. Turabian JL, Perez Franco B (2012) he symptoms in family medicine are not symptoms of disease, they are symptoms of life]. Aten Primaria 44(4): 232236.

12. Maranon G (1980) El dogmatismo médico y la Medicina antidogmática. En: La Medicina de nuestro tiempo. Madrid: Espasa Calpe, SA.

13. Parker I, Georgaca E, Harper D, Mclaughlin T, Stowell-Smith M (1995) Deconstructing psychopatology. SAGE Publications, London.

14. Epiphenomenon.

15. Tate A (2019) Matter over mind: How mental health symptom presentations shape diagnostic outcomes. Health: 1363459319834991.

16. Turabian JL (2017) Is The Meaning of Symptoms the Same in Women And Men? J Women's Health Care 6(3): 376.

17. Turabian JL (2018) Presentation and Approach of Disorganized Disease in Family Medicine. J Fam Med Forecast 1(1): 1001

18. Turabian JL (2018) Disorganized Diseases: Are they a Simple Explosion of Random Energy and therefore Meaningless? A Cases Series Study in Family Medicine. J Community Prevent Med 1(1): 18.

19. Turabian JL (2018) Hypothesis for a Theory about the Disorganized Health Problems in General Medicine: The Hidden Face of the Moon. Epidemol Int J 2(3): 1-7.

20. Nacul L, Lacerda EM, Kingdon CC, Curran H, BowmanEW (2019) How have selection bias and disease misclassification undermined the validity of myalgic encephalomyelitis/chronic fatigue syndrome studies? J Health Psychol 24(12): 17651769.
21. Foucault M (1996) El nacimiento de la clínica. Una arqueología de la mirada médica, Mexico, pp: 1-150.

22. Siebeck R (1957) Medicina en movimiento. Editorial Científico-Médica, Barcelona.

23. Andersen SB, Shapiro BJ, Vandenbroucke-Grauls C, de Vos MGJ (2019) Microbial evolutionary medicine: from theory to clinical practice. Lancet Infect Dis 19(8): PE273-E283.

24. Novelli F, Bacci E, Latorre M, Seccia V, Bartoli ML, et al. (2018) Comorbidities are associated with different features of severe asthma. Clin Mol Allergy 16: 25 .

25. Fry J (1987) Common diseases. $1^{\text {st }}$ (Edn.), Their nature, Incidence and Care. Springer Netherlands, Lancaster, England, pp: 432.

26. Turabian JL (1995) Notebooks for family and community medicine: an introduction to the principles of family medicine. Ediciones Díaz de Santos, Madrid.

27. Sen A (2002) Health: perception versus observation. BMJ 324(7342): 860-861.

28. Illich I (Translated by Antonio Cerella) (2017) The obsession with perfect health. J Cultural Res 21(3): 286-291.

29. Moreno ME (1995) Urgent health care and social demand: reflections on the choice of a response model. Emergencies 7(3).

30. Turabian JL, Perez Franco B (2015) Observations, intuitions and anecdotes, from the doctor's perspective, for a theory of the natural history of interpersonal continuity. The colors of time. Rev Clin Med Fam 8(2): 125-136.

31. Piller C (2019) Dubious diagnosis. Science 363(6431): 1026-1031.

32. Fort A (2018) How Do I Use the New Cholesterol Guidelines? Clin Rev 28(10): 18-19.

33. Editorial (2019) NICE hypertension guidelines: a pragmatic compromise. Lancet 394(10201): 806.

34. Rosenberg CE (2002) The Tyranny of Diagnosis: Specific Entities and Individual Experience. Milbank Q 80(2): 237-260.

35. Aronowitz RA (2009) The converged experience of risk and disease. Milbank 87(2): 417-442. 


\section{Epidemiology International Journal}

36. McCaffery KJ, Jansen J, Scherer LD, Thornton $\mathrm{H}$, Hersch J, et al. (2016) Walking the tightrope: communicating overdiagnosis in modern healthcare. BMJ 352: 348.

37. Kale MS, Korenstein D (2018) Overdiagnosis in primary care: framing the problem and finding solutions. BMJ 362: 2820.

38. Blech J (2005) Inventores de enfermedades: Como nos convierten en pacientes. Barcelona: Ediciones Destino.

39. Ruiz-Cantero MT, Cambronero-Saiz B (2011) Health metamorphosis: disease mongering and communication strategies. Gac Sanit 25(3): 179181.

40. Gavilan E, Jimenez de Gracia L, Gervas J (2014) [Strategies to promote testosterone deficiency syndrome: a paradigm of disease mongering]. Gac Sanit 28(2): 173-176.

41. Moynihan R, Brodersen J, Heath I, Johansson M, Kuehlein T, et al. (2019) Reforming disease definitions: a new primary care led, people-centred approach. BMJ Evid Based Med 24(5): 170-173.

42. Viejo Cordero T, Sangrador Rasero A (2005) Boletín de uso racional del medicamento 3.

43. Blanco-Uhlenhaut M, Saenz-Campos D (2003) Evaluacion clínica de la nefroproteccion de los bloqueadores de angiotensina II (ARA II). Acta Medica Costarricense 45(2).

44. Getz L, Sigurdsson JA, Hetlevik I, Kirkengen AL, Romundstad S, et al. (2005) Estimating the high risk group for cardiovascular disease in the Norwegian HUNT 2 population according to the 2003 European guidelines: modelling study. BMJ 331(7516): 551.

45. Chiolero A, Paradis G, Paccaud F (2015) The pseudo-high-risk prevention strategy. Int J Epidemiol 44(5): 1469-1473.

46. Alber K, Kuehlein T, Schedlbauer A, Schaffer S (2017) Medical overuse and quaternary prevention in primary care-A qualitative study with general practitioners. BMC Family Practice 18: 99.

47. Van Oostrom SH, Picavet HJ, Van Gelder BM, Lemmens LC, Hoeymans $\mathrm{N}$, et al. (2012) Multimorbidity and comorbidity in the Dutch population-data from general practices. BMC Public Health 12: 715.

48. Buitrago Ramirez F (2013) Methods for measuring the suitability of pharmacological treatment in the elderly with multiple conditions and on multiple drugs. Aten Primaria 45(1): 19-20.

49. Turabian JL (2019) Polypharmacy is an Indicator of Bad Practice and Low Quality in General Medicine. J Qual Healthcare Eco 2(4): 000130.

50. Turabian JL (2019) The increase of adverse drug reactions and drug-drug interactions are transforming diseases 'clinical symptoms. Journal of Health Care and Medicine. In Press.

51. Pagan Nunez FT, Tejada Cifuentes F (2012) Cascade Prescription and Description. Rev Clin Med Fam $5(2)$.

52. Kim S, Cheon SM, Suh HS (2019) Association between Drug Exposure and Occurrence of Parkinsonism in Korea: A Population-Based CaseControl Study. Ann Pharmacother 53(11): 11021110.

53. Turabian JL (2019) Reactions adverse to drugs and drug-drug interactions: a "wonderful" spiral of geometric growth produced by multimorbidity and polypharmacy. Journal of Clinical practice. In Press.

54. Hennessy S, Flockhart DA (2012) The need for translational research on drug-drug interactions. Clin Pharmacol Ther 91(5): 771-773.

55. Kolchinsky A, Lourenco A, Li L, Rocha LM (2013) Evaluation of linear classifiers on articles containing pharmacokinetic evidence of drug-drug interactions. Pac Symp Biocomput 409-420.

56. Turabian JL (2019) Approach to the Epidemiology of Drug Interactions in Primary Health Care. The Visible Part of a Dangerous Great Iceberg Growing Rapidly. Epidemol Int J 3(2): 1-10.

57. Turabian (2018) Strategies to Increase Opportunities to Identify and Communicate Adverse Drug Reactions and Drug Related Problems in General Medicine. J Family Med Community Health 5(6): 1165.

58. Turabian JL (2019) The role of general practitioner in the study of adverse drug reactions epidemiology in ambulatory care setting. Arch Community Med Public Health 5(1): 03-07.

59. Mangin D (2012) Beyond diagnosis: rising to the multimorbidity challenge. BMJ 344: e3526.

60. Kocarnik J (2019) Cancer's global epidemiological transition and growth. Lancet 6736(19). 
Epidemiology International Journal 